\title{
Ruptured intra-abdominal testicular seminoma with hemorrhage shock, after inadequate surgical exploration for undescended testis: a case report
}

\author{
Hirotake Gonda ${ }^{1,2}$, Takuya Saito ${ }^{*}\left(\mathbb{D}\right.$, Takaaki Osawa $^{1}$, Shintaro Kurahashi ${ }^{1}$, Tatsuki Matsumura', \\ Yasuyuki Fukami ${ }^{1}$, Shunichiro Komatsu' ${ }^{1}$ Kenitiro Kaneko' ${ }^{1}$ Kazuhiro Hiramatsu², Takehito Kato ${ }^{2}$ \\ and Tsuyoshi Sano ${ }^{1}$
}

\begin{abstract}
Background: Undescended testes are associated with an increased risk of malignancy and infertility, and surgical treatment in childhood is recommended.

Case presentation: A 35-year-old man presented to the emergency department with abdominal pain and vomiting. Despite a history of surgery for a left undescended testis in infancy, his left-sided scrotum appeared underdeveloped. Contrast-enhanced computed tomography showed a pelvic mass, involving a major axis of approximately $15 \mathrm{~cm}$, with high-density ascites suggestive of hemorrhage. A ruptured gastrointestinal stromal tumor was suspected. As he was in hemorrhagic shock, an emergency laparotomy was indicated. The active bleeding mass was controlled through complete resection. A pathological evaluation of the mass revealed a seminoma arising from an undescended testis. His post-operative course was uneventful, and he was discharged on post-operative day 6 . Recurrence on the retroperitoneal lymph nodes was detected 1 year postoperatively, and a retroperitoneal lymph node dissection was performed after chemotherapy. He remains well without any apparent signs of recurrence.
\end{abstract}

Conclusions: Paying close attention to an empty scrotum is advisable, even postoperatively, for undescended testis because of possible subsequent potential malignancy presenting with hemorrhage, as our patient demonstrated.

Keywords: Undescended testis, Seminoma, Intra-abdominal hemorrhage

\section{Background}

Undescended testes are a common birth anomaly [1]. Approximately $10 \%$ of undescended testes are located in the abdominal cavity, and an intra-abdominal testis has been reported to be at a higher risk of testicular cancer than an inguinal testis $[2,3]$. Orchiopexy is recommended at approximately 12 months of age to reduce the risk of testicular tumors and infertility $[1,2]$. However,

\footnotetext{
*Correspondence: tsaito0726@gmail.com

${ }^{1}$ Division of Gastroenterological Surgery, Department of Surgery, Aichi Medical University, 1-1 Yazakokarimata, Nagakute, Aichi 480-1195, Japan Full list of author information is available at the end of the article
}

undescended testes potentially remain in the abdominal cavity, even after orchiopexy, for various reasons [4]. Here, we report a patient with intra-abdominal hemorrhage from a left testicular seminoma in the abdomen. Although there are many reports of intra-abdominal testicular seminoma, presentation with hemorrhagic shock due to tumor rupture is extremely rare.

\section{Case presentation}

A 35-year-old married father of a newborn infant was transferred to the emergency department complaining of abdominal pain and an approximate $10-\mathrm{h}$ history of vomiting. He reported a surgical history 
of left undescended testis in infancy. He and his parents had noticed that his left scrotum was still small after the surgery, but they had not paid attention to it and had not seen a doctor. He denied any other significant medical or surgical history, or a history of injury. On admission, he was conscious, pale, and had a tachypnea. His blood pressure was $80 / 55 \mathrm{mmHg}$, his pulse rate was 130 beats/min, and he was in shock. On clinical examination, he presented with abdominal distention and diffuse tenderness with guarding. His blood test results showed a low hemoglobin concentration $(9.2 \mathrm{~g} / \mathrm{dl})$ and an elevated white blood cell count $\left(21,200 / \mathrm{mm}^{3}\right)$. Contrast-enhanced computed tomography $(\mathrm{CT})$ revealed a large volume of highdensity ascites and a large mass, with a major axis of approximately $15 \mathrm{~cm}$ in the pelvic area. The mass was poorly attenuated and contained blood vessels (Fig. 1). There was no evidence of suspected metastasis to other organs or lymph nodes, paracentesis confirmed bloody fluid. We diagnosed hemorrhagic shock due to rupture of the pelvic mass, which was suspected to be a gastrointestinal stromal tumor. He was infused with $2500 \mathrm{ml}$ of extracellular fluid preoperatively. Blood pressure improved with infusion, but decreased when the administration rate was slowed. We decided to perform an emergency laparotomy. It took $110 \mathrm{~min}$ from the admission to the start of the surgery. On opening the abdomen, approximately $1500 \mathrm{ml}$ of bloody fluid and a torn mass with active bleeding were encountered. The mass was easily elevated to the outside and was only connected by a pedicle containing the left gonadal artery and vein (Fig. 2). The pedicle was twisted approximately $180^{\circ}$. The left gonadal artery and vein were ligated and divided, and the mass was excised. The mass was $16 \times 12 \times 9 \mathrm{~cm}$ in size and weighed $840 \mathrm{~g}$. The operating time was $77 \mathrm{~min}$, and the total blood loss was $1647 \mathrm{ml}$. He received 4 units of RBCs and $2000 \mathrm{ml}$ of fluid infusion during surgery. The post-operative course was uneventful, and he was discharged on post-operative day 6. The cut surface of the soft tumor was composed of solid nodules with areas of hemorrhagic necrosis surrounded with a thin capsule. Histologic examination revealed clear tumor cells arranged in sheets with large, rounded nuclei proliferation and lymphocyte infiltration. There was neither vascular nor capsular invasion. The patient was diagnosed with a seminoma arising in the undescended testis (Fig. 3). Intra-operative ascites cytology showed no malignancy. No distant metastasis or lymph node metastasis was found on laparotomy and pre-operative $\mathrm{CT}$, and his pathological staging was stage IA (pT1NOM0). Post-operative palpation demonstrated an absence of the left testis, resembling an empty scrotum. He had a surgical scar on his left inguinal region, but no other surgical scars could be identified. After discharge, he was followed up at the urology department of our hospital. One year following surgery, lactate dehydrogenase and alpha-fetoprotein tumor markers were found to be within normal limits; however, the human chorionic gonadotropin

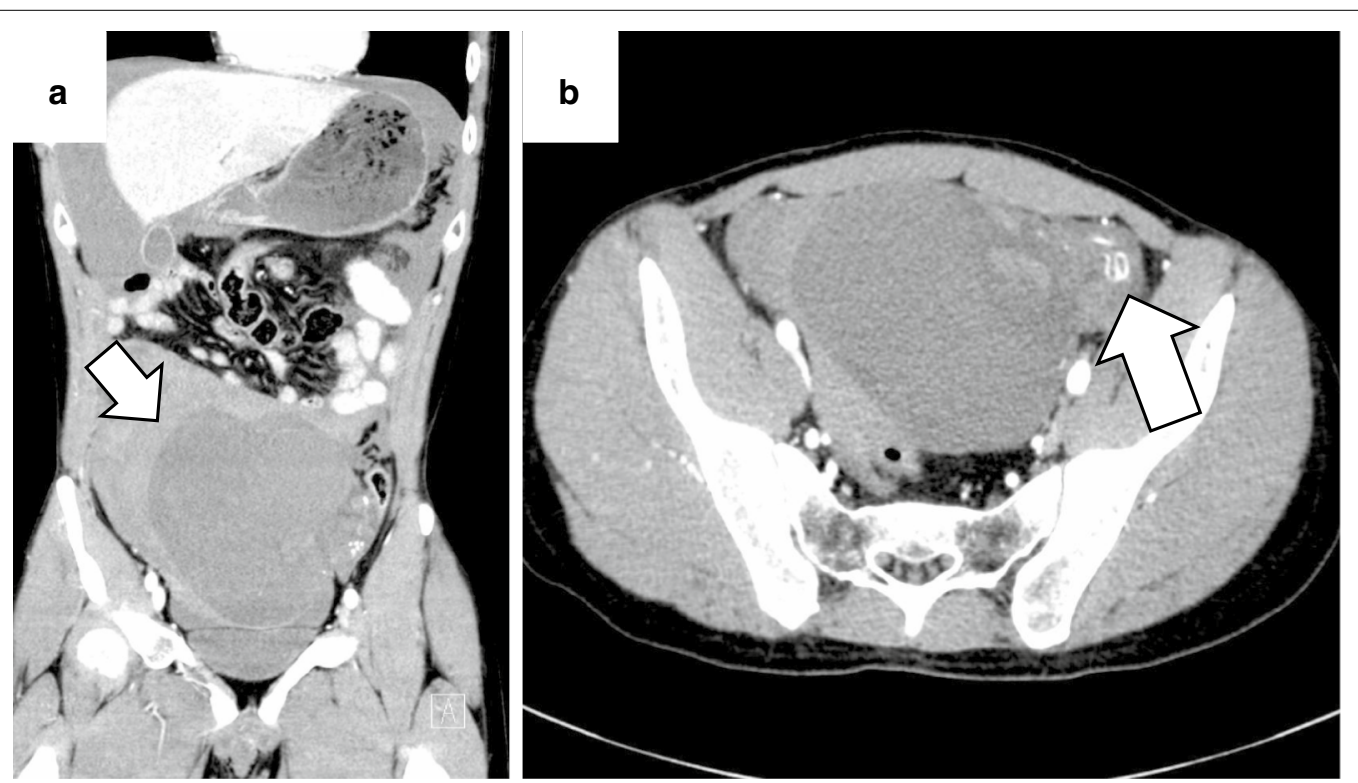

Fig. 1 a A large volume of high-density ascites in the abdominal cavity and a huge mass in the pelvis were observed. b The contrast enhancement effect of the mass was poor, and blood vessels were observed inside the mass (arrow) 

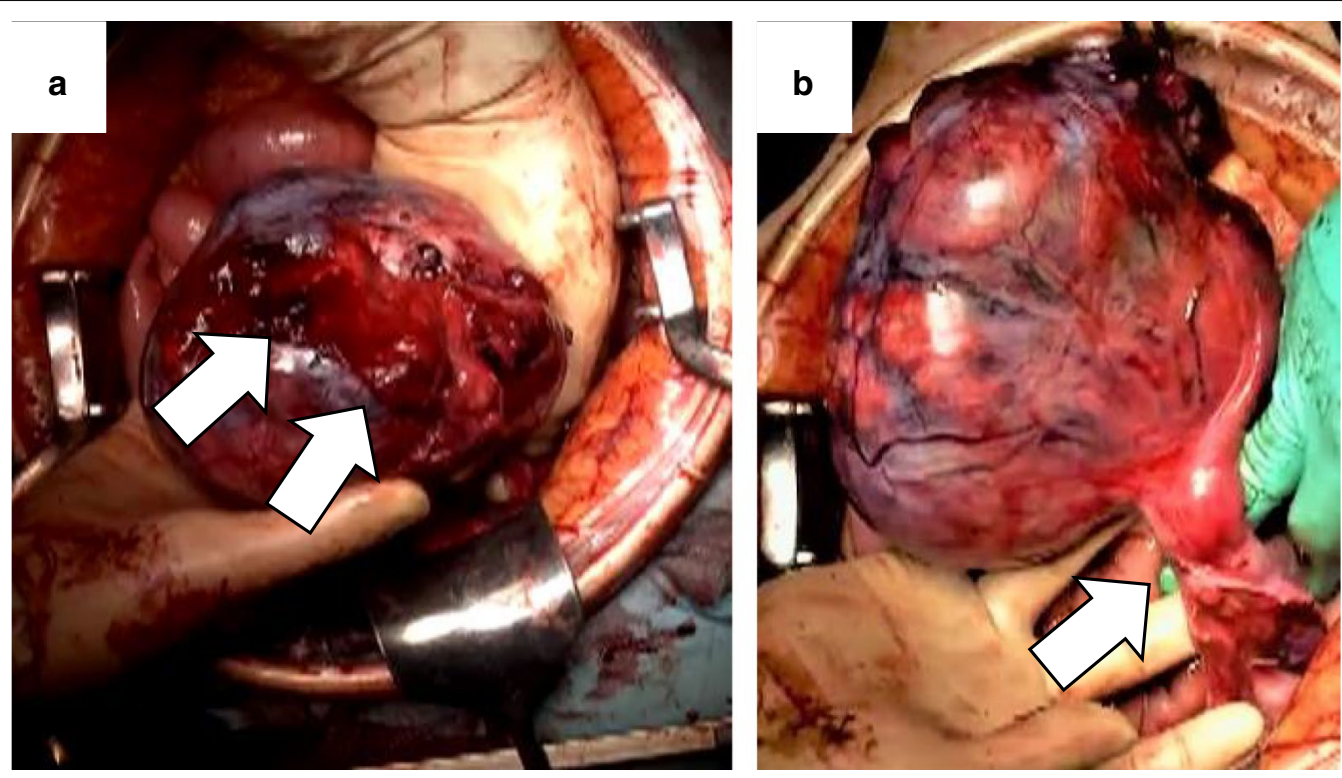

Fig. 2 a The capsule of the mass was torn and caused bleeding (arrow). b The mass was connected by the feeding vessels of the left gonadal artery and vein only (arrow)
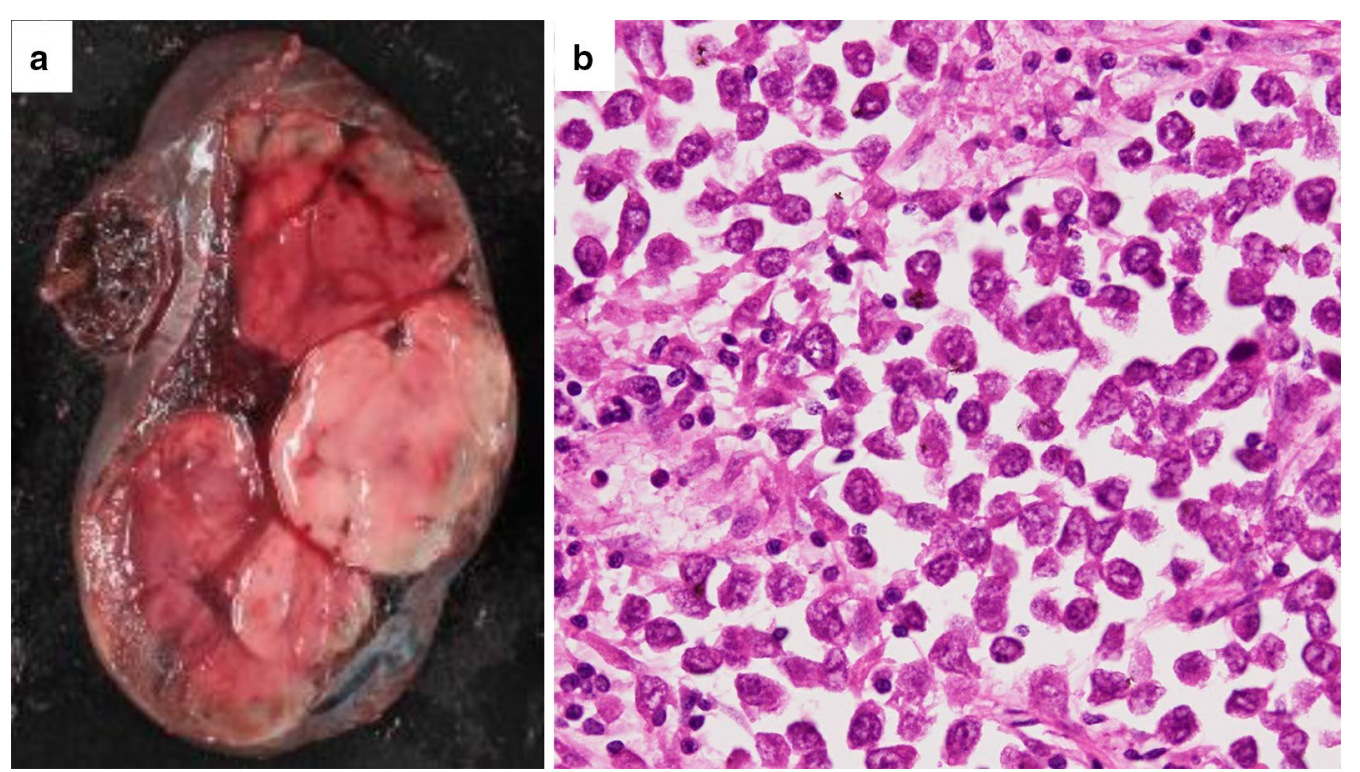

Fig. 3 a Gross photograph of the mass cross-section. Solid tumor covered with a thin capsule showing internal necrosis and hemorrhage. b Tumor cells with large circles are arranged in sheets, with finely vacuolated cytoplasm, and nuclei with distinct nucleoli of the tumor cells are round. Infiltration of lymphoplasmacytic cells is observed (hematoxylin and eosin stain, 400x)

level was elevated. CT results revealed retroperitoneal lymph node recurrence. After three cycles of chemotherapy with bleomycin, etoposide, and cisplatin $\left(20 \mathrm{mg} / \mathrm{m}^{2}\right.$ cisplatin on days $1-5,100 \mathrm{mg} / \mathrm{m}^{2}$ etoposide on days $1-5$, and $30 \mathrm{kU}$ bleomycin on days 1,8 , and 15 , repeated 21 days), he underwent retroperitoneal lymph node dissection by transperitoneal approach by open surgery. Histological examination of dissected lymph nodes showed fibrous scarring with no residual tumors. One year after the radical retroperitoneal lymph node dissection, he remains well without any signs or symptoms of tumor recurrence. 


\section{Discussion}

This patient presented with shock due to bleeding from an abdominal tumor, for which the treatment of choice is an emergency laparotomy irrespective of a pre-operative diagnosis of the tumor. Our patient had a history of surgery for a left-sided undescended testis in infancy; however, the medical records for surgery and post-operative follow-up were not available. The intra-abdominal bleeding was due to rupture of a seminoma arising from the remnant testis. Post-operative examination and palpation indicated a left empty scrotum. The potential cause of intra-abdominal remnant testis even after orchiopexy is considered to be due to post-operative testicular retraction [5] or intra-operative inadequate confirmation of the intraperitoneal testis [6]. Polyorchidism with more than three testes per individual has also been reported [7], and it is possible that only one testis was treated during orchiopexy. He only had a surgical scar on his left inguinal region, which suggested inadequate surgical exploration for the undescended testis. The fact that he and his family had noticed the empty scrotum even after the surgery for the undescended testes, but had not followed up, could also have been a problem. According to the "evaluation and treatment of cryptorchidism: AUA guidelines" published in 2014 [8], it is recommended that boys who have undergone treatment for undescended testes be taught how to perform testicular self-examination during adolescence and instructed to perform the examination monthly because the risk of testicular malignancies is still higher even after the reposition of the undescended testis.

The pathological staging of this case was stage I. For stage I testicular seminoma, radical inguinal orchiectomy is the first choice. Standard options after surgery include active surveillance, radiation therapy or 1-2 cycles of carboplatin [9]. In this case, active surveillance was performed postoperatively.
Malignant tumors arising from undescended testis have no characteristic symptoms; therefore, early determination can sometimes be challenging [10]. Enlarged intra-abdominal testicular tumors may cause urinary frequency due to bladder compression, bowel obstruction, torsion of the pedicle, and rupture with or without hemorrhage, according to tumor size [11].

A precise pre-operative diagnosis can offer reasonable or ideal surgical strategies for abdominal tumors. According to the condition of a patient with a ruptured abdominal tumor, interventional radiology may affect the post-operative course in terms of temporal hemostasis or reduction of blood inflow. Stabilization and recovery from the shock status generally allow for pre-operative therapies or less invasive surgery, including laparoscopic resection. A pre-operative diagnosis is critical to perform an appropriate urgent surgical procedure to control intra-abdominal hemorrhage immediately. For this patient, the necrotic and ruptured tumor had a thin distorted stalk containing the left gonadal artery and vein, which were connected to the inguinal region. Thus, torsion of the undescended testicular tumor's pedicle was suspected immediately following the laparotomy. Our pre-operative diagnosis was not sufficiently precise, even on second look and review of the pre-operative CT. He was in shock on admission preoperatively, so we were unable to perform the full physical examination, including the scrotal examination. If we had noticed his empty scrotum before surgery, we would have suspected an intraabdominal testicular tumor and first found and ligated the gonadal artery and vein, the feeding vessel of the mass, when we opened the abdomen.

Intra-abdominal hemorrhage from a seminoma arising from an undescended testis located in the abdominal cavity is a rare condition, with only five reports since 1970 of bleeding due to an intra-abdominal seminoma

Table 1 The literature review of cases of intraperitoneal hemorrhage from rupture of intra-abdominal testicular seminoma

\begin{tabular}{|c|c|c|c|c|c|c|}
\hline References & Age (years) & $\begin{array}{l}\text { Past surgery } \\
\text { of undescended testis }\end{array}$ & Operation & $\begin{array}{l}\text { Metastasis at initial } \\
\text { diagnosis }\end{array}$ & $\begin{array}{l}\text { Length of post- } \\
\text { operative stay (days) }\end{array}$ & Recurrence \\
\hline [12] & 17 & No & Tumor resection & No & 7 & No \\
\hline [13] & 38 & Yes & Tumor resection & No & 5 & Not listed \\
\hline [14] & 28 & No & Tumor resection & No & 7 & Not listed \\
\hline$[15]$ & 30 & No & Tumor resection & No & 3 & No \\
\hline$[16]$ & 30 & No & Tumor resection & No & Not listed & No \\
\hline Current report & 35 & Yes & Tumor resection & No & 6 & $\begin{array}{l}\text { Retroperito- } \\
\text { neal lymph } \\
\text { node }\end{array}$ \\
\hline
\end{tabular}


[12-16] (Table 1). According to these reports, one patient had a history of previous surgery for an undescended testis [13]. All five patients had undergone tumor resection, and distant or lymph node metastasis was not detected in pre-operative and/or intra-operative findings. Although acceptable post-operative short-term outcomes were described in all cases, the long-term results regarding tumor recurrence remain unclear. A collation of seminoma cases arising from an undescended testis and a comparison with an ordinal seminoma is warranted to delineate the biological nature and clinical effects of such seminomas on long-term outcomes.

\section{Conclusion}

We report a patient with an intra-abdominal testicular seminoma who was in hemorrhagic shock due to tumor rupture. An intra-abdominal seminoma may develop, even after previous orchiopexy surgery for undescended testes, and careful observation of an empty scrotum is advisable.

\section{Abbreviations}

CT: Computed tomography; GIST: Gastrointestinal stromal tumor.

\section{Acknowledgements}

None.

\section{Authors' contributions}

HG drafted the manuscript. SK contributed to the interpretation of the data and critical revision of the manuscript for important intellectual content. TA, TO, SK, TM, TS, SK, KK, KH, TK, and TT contributed to the data collection and interpretation and critically reviewed the manuscript. All authors read and approved the final manuscript.

\section{Funding}

The author(s) received no financial support for the research, authorship, and/ or publication of this article.

\section{Availability of data and materials}

The datasets supporting the conclusions of this article are included within the article and its additional files.

\section{Declarations}

Ethics approval and consent to participate Not applicable.

\section{Consent for publication}

Written informed consent was obtained from the patient for the publication of this case report and any accompanying images.

\section{Competing interests}

The authors declare that they have no competing interests.

\section{Author details}

${ }^{1}$ Division of Gastroenterological Surgery, Department of Surgery, Aichi Medical University, 1-1 Yazakokarimata, Nagakute, Aichi 480-1195, Japan. ${ }^{2}$ Department of Surgery, Toyohashi Municipal Hospital, Toyohashi, Aichi, Japan.

Received: 7 December 2020 Accepted: 22 February 2021

Published online: 08 March 2021

\section{References}

1. Kurz D. Current management of undescended testes. Curr Treat Options Periatr. 2016;2:43-51.

2. Niedzielski JK, Oszukowska E, Słowikowska-Hilczer J. Undescended testis - current trends and guidelines: a review of the literature. Arch Med Sci. 2016;12:667-77.

3. Pettersson A, Richiardi L, Nordenskjold A, Kaijser M, Akre O. Age at surgery for undescended testis and risk of testicular cancer. N Engl J Med. 2007;356:1835-41.

4. Pesce C, D'Adontino S, Costa L, Musi L, Manzi M. Reoperative orchiopexy: surgical aspects and functional outcome. Pediatr Surg Int. 2001;17:62-4.

5. Herrinton LJ, Zhao W, Husson G. Management of cryptorchism and risk of testicular cancer. Am J Epidemiol. 2003;157:602-5.

6. Brothers LR 3rd, Weber CH Jr, Ball TP Jr. Anorchism versus cryptorchidism: the importance of a diligent search for intra-abdominal testes. J Urol. 1978;119:707-8.

7. Singer BR, Donaldson JG, Jackson DS. Polyorchidism, functional classification and management strategy. Urology. 1992;39:384-8.

8. Kolon TF, Herndon CD, Baker LA, Baskin LS, Baxter CG, Cheng EY, et al. Evaluation and treatment of cryptorchidism: AUA guideline. J Urol. 2014;192:337-45.

9. Chovanec M, Hanna N, Cary KC, Einhorn I, Albany C. Management of stage I testicular germ cell tumours. Nat Rev Urol. 2016;13:663-73.

10. Miller FH, Whitney WS, Fitzgerald SW, Miller El. Seminomas complicating undescended intraabdominal testes in patients with prior negative findings from surgical exploration. Am J Roentgenol. 1999;172:425-8.

11. Nkembe MN, Mvalo CM, Tianyi FL, Demba C. Ambiguous presentation of intra-abdominal testicular seminoma in a 40-year-old man: a case report. J Med Case Rep. 2019;13:2.

12. Watkins GL. Massive hemoperitoneum resulting from rupture of a seminoma in an undescended testicle. J Urol. 1970;103:447-8.

13. Küçük HF, Dalkiliç G, Kuroğlu E, Altuntaş M, Barişik NO, Gülmen M. Massive bleeding caused by rupture of intra-abdominal testicular seminoma: case report. J Trauma. 2002;52:1000-1.

14. Singh P, Bajaj K, Kaur R, Mishra A, Riar H. Ruptured seminoma of undescended testis presenting as acute abdomen: case report with literature review. Ann Med Health Sci Res. 2013;3:108-9.

15. Nickalls OJ, Tan CL, Thian YL. A Torted ruptured intra-abdominal testicular seminoma presenting as an acute abdomen. J Radiol Case Rep. 2015:9:21-8.

16. Diwakar DK, Wadhwani N, Pradhan RS, Verma RP. Spontaneous rupture of seminoma in undescended testis with hemoperitoneum: a rare presentation. BMJ Case Rep. 2018. https://doi.org/10.1136/bcr-2018-224898.

\section{Publisher's Note}

Springer Nature remains neutral with regard to jurisdictional claims in published maps and institutional affiliations. 